\title{
Montagn's Ornithological Dictionary; new edition, "with a plan of study, and many new articles and original observations
}

James Rennie A.M. A.L.S.

To cite this article: James Rennie A.M. A.L.S. (1831) Montagn's Ornithological Dictionary; new edition, "with a plan of study, and many new articles and original observations, Philosophical Magazine Series 2, 10:59, 370-379, DOI: $10.1080 / 14786443108675560$

To link to this article: http://dx.doi.org/10.1080/14786443108675560

曲 Published online: 14 Jul 2009.

Submit your article to this journal \lceil

Џ Article views: 2

View related articles $\sqsubset$ 
XLVIII. Notices respecting Nerv Books.

Montagr's Ornithological Dictionary; new edition, " with a Plan of Study, and many new Articles and original Observations. By James Rennie, A.M., A.L.S., Professor of Natural History, King's College, London; Author of 'Insert Architecture,' ' Insect Transformations,' 'Architecture of Birds,' \&c." London, 1831. Octavo ; Introduction, \&c. pp. 1x., Dictionary and Index, pp. 592 ; 28 Engravings on Wood.

“On my plan, any person, with a little care, may become a tolerably good naturalist, the first walk he takes in the fields, without much knowledge of books."-Mr. Rennie's Introduction, p. iv.

THE Editor of this new edition of Montagu's Ornitho logical Dictionary, and author of the introductory matter now prefixed to that work, has recently been appointed to the chair of Natural History in the King's College of London, (that is, we suppose, to the chair of Zoology, since Mr. Burnett is Professor of Botany.) Having been known to science previously only by the compilations (interspersed with some observations of his own), of which he is stated to be the author in the title-page quoted above, and which form part of the Library of Entertaining Knowledge, he has undertaken the publication now before us, we presume, for the purpose of evincing his fitness for the duties, as Professor of Zoology in one of our new national establishments for scientific education, which have been committed to his charge. He has also still more recently announced, in pursuance, we presume, of the same purpose, his intention of publishing "A Conspectus of Butterflies and Moths," and a translation "with copious notes and synonymes" of Le Vaillant's "Birds of Africa," "Birds of Paradise," and "Parrots."

We proceed, therefore, to examine the claims to regard as a man of science and as a public teacher of zoology, which Mr. Rennie has asserted in the volume now under our consideration.

The introductory matter is arranged under the following heads : "Introduction,"-_"Plan of Study,"-" "The Use of System,"-_"System of Linnæus and Latham,"-_" The Quinary System and Modern Doctrine of Types, Affinities, and Analogies,-and "Catalogue of Naturalists," subdivided into "Rudimental Naturalists,"- "Literary Naturalists,"- - and "Philosophic Naturalists, and Original Observers."

On perusing this introductory mattter from p. iii. to.p. $1 x$., we were struck with the extreme assumption and arrogance of the whole style of treating his subject, which is here displayed by the author; with the bitterness and contempt of his vituperation of the naturalists whose views he condemns, disingenuously mingled with pritise, which on his own showing must be undeserved; and with the perverse ignorance from which alone such misrepresentations as he makes on all the subjects which he touches, could have arisen. We affirm, in limine, that his statements respecting the Quinary System and every subject connected with it, are a tissue of errors, from beginning to end. He 
does not understand any of the subjects he has undertaken to discuss; he cites his own blunders as characters and attributes of the systems he impugns, and then actually takes credit to himself for overthrowing them. There is no such thing in the entire introduction as a fair statement or an examination of any of the systems he proposes to consider ; all is arrogant, unsupported assertion, mingled with garbled extracts. His criticism of the various systems of ornithology or of zoology in general, is exceedingly confused and intricate, and difficultly intelligible; and many of his observations are utterly inapplicable, referring only, in reality, to his own misconceptions of the systems impugned.

Conscious, apparently, of the charges that would be preferred ayainst him, on account of the misrepresentations which we have now briefly characterized, Mr. Rennie, in p. v. of his "Introduction," offers the following apologetical remark :

"The offer to print any reply to my arguments, which might be sent me, exculpates me, I conceive, from all charges of a personal nature; and it would grieve me much, if my dislike to their doctrines and language [those of Mr. W. S. Macleay and his disciples] has, in any instance, betrayed me to infringe upon the courtesy and decorum which ought uniformly to characterize such discussions. To enter into any compromise with error, would be unpardonable weakness and delinquency; but to endeavour, by contempt or abuse, to hurt the feelings of the person judged to be in error, would exhibit the character of a bully or a ruffian."

But we will tell Mr. Rennie, that the offer to print any reply to his arguments that might be sent him, afiords no excuse whatever for making false representations, (and many such has he made) which must necessarily have an effect upon the public mind unfavourable to the subjects of them, before the replies can appear. As well might the defamer of the character of any private individual hold himself exculpated from the charge of slander, by his offer to print a denial of his unjust representations, after they had gone forth to the world, to the injury of the object of his attack. It is difficult to conceive, also, that Mr. Rennie's professions of sorrow, if he should be found to have been betrayed into an infringement of the courtesy and decorum which ought to characterize scientific discussions, can be sincere, when we observe, in almost every page of his portion of this volume, the most palpable violations of courtesy, of decorum, and of truth. What his intentions may have been it is impossible for us absolutely to know, but it is certain that the pages before us present many examples of contempt and abuse, which in their own intrinsic quality, would become only those characters to which $\mathrm{Mr}$. Rennie, in the concluding sentence of the above extract, has rightly ascribed the exhibition of them.

We now proceed to prefer against Mr. Rennie, seriatim, the charges which, as it appears to us, he has justly incurred by the representations made in the introductory matter to his edition of Montagu's Ornithological Dictionary now before us. We pledge ourselves to prove these charges, by the most ample and satisfactory evidence, as we proceed in this review. We shall intersperse them now with various facts re$3 \mathrm{~B} 2$ specting 
specting Mr. Rennie's character as a naturalist, which the perusal of the introductory matter discloses. His incapacity for the office he has assumed of Editor of Montagu's work, will be made abundantly evident hereafter.

$\mathrm{Mr}$. Rennie appears to be wholly ignorant of the higher philosophy of Natural History, considered either as a branch of science, as a means of training the mind to the love of truth, or as an instrument of leading it to the admiration and adoration of the Creator. He seems to have little knowledge or perception of the vastness of nature, and none whatever of the fact, that there are such things as design and order in the distribution of the beings and substances which compose it.

He arrogantly misrepresents the scientific character of Linnæus, most disingenuously adopting the remarks upon it made by $\mathrm{Mr}$. W. S. Macleay and some of the naturalists of the School he has founded, which have been suggested to them by their peculiar views; views upon which he afterwards heaps abuse, and still more deeply misrepresents.

His opinions of the merits of the various investigators of nature whom he has occasion to mention, of the highest rank in their respective departments of science, are pronounced in the most conceited and unbecoming manner : the most eminent and learned naturalists, whether practical observers or systematists, are equally the objects of his contempt : thus we have " the dry, lifeless, marrowless, and unphilosophic descriptions of the Linnæan school" (p.xxv.); their "gross inaccuracy" ( $\mathrm{p} . \mathrm{xxx}$.) ; the "Linnæan barrenness of iden and of deduction" (ib.); the "hot and testy" behaviour of Linnæeus (p. xxxvii.); the "briefness and poverty" of Pennant (p. xxvi.); the "credulous absurdity" (ib.) and the "wild, mischievous, and most absurd analogies" (j. xlviii.) of Cuvier ; and the "trash" of Mohs and Haidinger (p. xxvii.)*

Mr. Rennie further betrays the most palpable want of knowledge of the ordinary meaning conveyed by common forms of expression. He mingles some portious of the nomenclature of the Quinary System, in an insidious manner, with the monstrous errors and absurdities

* In the Englishman's Magazine for August last is an article entitled "Mismanagement of the Library of the British Museum," which we have been informed is from the pen of Mr. Rennie. Its style in every respect corroborates this information, exactly resembling that of the prefatory matter to Montagu. We mention it here, because Mr. W. S. Macleay's Annulosa Javanica is characterized in it (p.589) as a "flimsy production," the "effrontery" of its " presumptuous author" being mentioned ; while Dr. Horsfield's Lepidopterous Insects is stated to be a "worthy companion" to the Annulosa' Javanica, being, therefore, also "a fiinsy production" manifesting the "effrontery"of its " presumptuous author."-The flimsy productions, effrontery, and presumption of Mr.W.S. Macleay and of Dr. Horsfield! authors of some of the most splendid discoveries and profound researches in zoology which have ever been accomplished, and whose reputation is spread throughout the civilized world! To what part of the duties of Professor of Natural History in the King's College of London does this treatment of two of the most eminent cultivators of that science belong ? 
which he has ignorantly confounded with that system, so as to induce the reader who is previously unacquainted with the subject, to conclude that $\mathrm{Mr}$. Rennie's representations must needs be founded in truth, when he would have had nothing but Mr. Rennie's assertions to support that conclusion, had an ingenuous plan been pursued.

In the most false and unfounded manner he confounds the atheistical doctrine of appetencies, broached by Darwin, Lamarck, and Robinet, with the Macleayan doctrine of the progression in affinity from one group of animals to another, or the variation of form of each species from that possessed by the preceding one, so that on examining the entire group, a progressive change of character is observable, made up of the separate differences between each pair of contiguous species. He asserts, with equal violation of the truth, that the Quinary System, "while it professes to reject this strange docirine, at the same time adopts its very language in the most unequivocal manner." (p. xxxiii.) The truth being, that the doctrines respecting natural distribution, held and advocated by Mr. Macleay, or more properly speaking the phonomena which he has discovered in the progression of affinities, \&c. in natural history, afford the most triumphant refutation of the doctrine of appetencies; and that the entire scope of some of Mr. Macleay's arguments is directed against the very errors in zoology upon which that doctrine is founded.

To support these misrepresentations, Mr. Rennie affirms, with equal falsity, thit $\mathrm{Mr}$. Macleay has borrowed some of his general expressions from Robinet, and, as be would insinuate, with the intention of imparting the same ideas as that writer. (p. xxxv.) He further expressly asserts, with the same want of truth, that Mr. Macleay's "doctrine of types" is "directly borrowed from the atheistic system of Robinet." (p.xxxviii.) The Rev. W. Kirby, one of the authors of the celebrated "Introduction to Entomology," a work which is distinguished by the strain of rational piety and fervent devotion which it breathes, not less than by its accurate scientific details, is charged (p.xxxvii. \&.c.) with adopting (from Macleay) the atheism of Robinet! The extreme effrontery of this, (as we are sure all our readers will unite with us in regarding it,) becomes more strikingly apparent, when we reflect that the venerable naturalist thus accused was, not long since, selected to produce one of the works to be published in demonstration of the Divine Attributes, as manifested in the Works of the Creation, in pursuance of the bequest of the late Earl of Bridgwater. That this was a peculiarly appropriate selection, all who are acquainted with the works of $\mathrm{Mr}$. Kirby, will concur in thinking; and what renders the most unfounded attack upon him in the publication before us the more extraordinary, is that it should proceed from a Professor in a College, two of the Governors of which (the Archbishop of Canterbury and the Bishop of London) concurred with the President of the Royal Society (then Mr. Davies Gilbert) in the appointment of Mr. Kirby to the above office *.-But to return to Mr. Rennie. Pursuing the same strain, Messts. Macleay and Kirby are actually both charged, in the

* Sce Phil. Mag. and Aunals, N.S. vol, ix. p. 202. 
page last quoted, with assuming " that a stone has improved itself into an oak, and a horse into a man!" The idea of deviation in structure from a type previously discovered by an inductive process, or that of the assemblage of characters which belong to the species forming the aberrant groups of $\mathrm{Mr}$. Macleay, is confounded in the work before us with the notion of absolute imperfection and degradation in the works of the Creator. The mental process by which we express the gradual change of form and structure observable in the progression of affinities among animals, is mistaken by Mr. Rennie for the actual physical conversion of one animal into another by the exercise of its own volition, and Mr. Macleay is charged with advocating the latter doctrine! The most philosophical and profound deductions of the most eminent naturalists of all ages, are also stigmatized by him as being nothing but the vagaries of fancy.

Finally, Mr. Rennie, rightly anticipating that he would be charged with misrepresenting the Macleayan System, and the opinions of its discoverer and advocates, attempts to excuse himself by confounding his own groundless inferences with the mistakes regarding the subject, of certain naturalists whom he names, but whom we will not degrade by naming unnecessarily in the same page with him.

We here terminate our indictment of Mr. Rennie at the bar of scientific and literary justice, for the numerous misrepresentations of fact, and misinterpretations of reasoning, of which the introductory matter of his edition of Montagu's Ornithological Dictionary is composed; and we proceed to state the process we have adopted in order to obtain the evidence necessary to support our charges, and the manner in which we intend to bring it forward.

Agreeably to Mr. Rennie's invitation in p. xxi. we have weighed " every fact" which he has adduced; we have "rigidly" scrutinized "every inference" he has made; and having found them wholly "wanting in truth and accuracy," "at once," as he calls upon us to do, "without any compromise," we " reject them." And, in accordance with our duty as conductors of a scientific Journal, we intend, by detailing the results of our weighing of facts and sarutiny of in. ferences, to evince that our readers also must. "without any compromise," "reject" Mr. Rennie and his works, as having any claim to the attention of the cultivators or students of science, or to that of the admirers of nature.

All the representations concerning $\mathrm{Mr}$. Rennie's mode of treating the subjects he has undertaken to discuss, which are preferred in the foregoing pages, we engage to substantiate in detail, refuting at the same time such of his assertions as may appear to require it, in the course of the present article. In doing this, we shall have occasion to enter into an examination of certain errors respecting the "new views" in Natural History, which, as we conceive, have been committed by several contemporary naturalists ; but we shall most carefully distinguish their candid criticism and expression of their sentiments from the arrogant and baseless assertions of Mr. Rennie, which involve the same fallacies of reasoning. We shall also endeavour, as we proceed, to explain and define, in their true characters, 
the views of natural arrangement of Mr. Macleay and his disciples, so far as they have yet been enunciated; noticing some differences of opinion, on minor points, which exist among the naturalists of this school. By this means we hope to convey a just idea of them to the general reader ; for we wish to enlist every reflecting mind interested in the study of nature, in the support of the "new views," confident alike of the delight which the truths they unfold will convey to every person of common intellectual powers, and of the increased stability they will be found to give to the deductions of a sound natural theology, harmonizing most perfectly with the Christian Religion.

For reasons which will be evident in the sequel, we begin with Mr. Rennie's attack on the Quinary System. This commences in p. xxxii. of his prefatory matter, and in the following page, uncler the head "The Quinary System and Modern Doctrine of Types, Affinities, and Analogies," he ostensibly begins the consideration of the subject. Mr.W.S. Macleay's attempt to discover the natural system he states to have been "beyond all question, highly laudable," though, he contin ues, "I shall endeavour to show, after giving a brief outline [of it], it appears to be altogether a failure." Mr. R. then gives an extract from a review published in the Zoological Journal, and four extracts from Mr. W. S. Macleay's own works, for the purpose, apparently, of supporting a representation which he makes at the outset, that the "system recently proposed," to which he is about to advert, "on its first announcement, put forth the high claim of being exclusively,if not the natural system, at least the rudiments thereof, or furnishing the means for arriving at this, and, therefore, [of being] in accordance with the plan of the Deity at the creation."

Now with this representation of the character of the doctrine of the circular succession of affinities and the parallelism of groups, (as we shall for the present designate the system under examination, for the particular number of the groups it discovers is merely a consequence of its other principles, ) we heartily concur. To maintain that the arrangement discovered by Mr. Macleay is the entire system of nature, - that it embraces the whole plan of the Deity at the creation, or that errors may not exist in what Mr. Macleay or his followers may have promulgated as the result of their observation of nature, would be idle and absurd; and we confidently affirm that such a view never has been maintained either by Mr. Macleay or his disciples.

But we also affirm that the system first propounded, as a system, by Mr. Macleay, and discovered by him (however certain constituent principles of it might have been previously discovered by others) is as much "the natural system" as the Copernican system of that assemblage of the heavenly bodies of which the planet we inhabit is one, is "the natural system". Everything that proceeds from the mind or the hands of man, is, in the universal sense of the term, artificial; for what is produced by the exertion of the human mental faculties, or the human corporeal organization, cannot be natural, cannot be, ipso facto, what exists in nature. But when nature is observed by man, and when man expresses in language or by visible signs, his conception of what he has thus observed in nature, the logical or predicative 
system, or assemblage of observed truths, so produced, is, in the language of science, the natural system. Thus what we call the "Copernican System" of nature, (truly, be it observed, a natural system, is not the actual assemblage of planetary bodies circulating round the sun, of which our planet forms a part, but it is a representation of it, exactly corresponding to the truth; being all that man can know of the reality. We make these remarks in this place, because much needless misapprehension, and also much unprofitable discussion, have taken place on this part of the subject, and on the right use of the phrase "the natural system". The expression, by man, of the truths he has discovered respecting the system of nature, if that expression be itself true, is, in the just and legitimate sense of the term, "the natural system"; being all that a finite being can know or possess of it.

We further maintain that this is the sense, and the only sense, in which the phrase "the natural system", and other equivalent terms, have ever been used by Mr. Macleay and the naturalists of the modern Britisi School of Zoology, of which he is the founder ; and that it is the sense, and the only sense, of that phrase, and of the allusions to the same subject, as employed in the extracts cited by Mr. Rennie, in the page now before us.

In the extract from the review in the Zoological Journal, Mr. Macleay is characterized as " that profound zoologist who has succeeded more effectually than any of his predecessors in unravelling the intricacies of the system pursued by Nature in the distribution of the animal kingdom". What can be more explicit than this ? the very identical system propounded by $\mathrm{Mr}$. Macleay is not regarded as being "the system pursued by nature", but he is sajd to have been more successful than his predecessors in unravelling the intricacies of that system ; just as we might say that Haüy was more successful than his predecessors in unravelling the intricacies of the system "pursued by nature" in the production of crystallized minerals ; or that Mr. Dalton has been more successful than his predecessors in unravelling the intricacies of the system "pursued by nature" in the constitution of chemical combinations.

Mr. Rennie's statement insinuates, though it does not broadly affirm, that $\mathrm{Mr}$. Macleay identifies his views with the actual system of nature, as existing in nature; now this we positively deny, and we deny too, that such a sense can be fairly or honestly extracted from the passages quoted. After laving examined the preface to the Hore Entomologice, from which Mr. Rennie's first two quotations are made, we affirm that no approach to such an identification is contained in it. The reader will observe that in these passages Mr. Macleay does not once mention his own views, but merely places in apposition "an artificial system" (understanding thereby any such system) and "the natural system" - " the plan of the creation itself- the work" of an all-wise, all-powerful Deity". But he would suppose, from the connection in which the extracts are introduced by Mr. Rennie, that where "the natural system" is mentioned in them, Mr. Macleay means his own individual views. Than this, however, nothing can 
be further from the truth; Mr. Macleay does not, in the entire course of his preface, even once etther expressly make or indirectly imply such an identification. He speaks throughout of the natural system as a thing which it is the end of the pursuit of natural history to discover, not as a thing yet discovered by any naturalist, and not at all as having been discovered by himself. Nor can the assumption $\mathrm{Mr}$. Rennie would insinuate be discovered, (neither is it in the smallest degree implied,) in the quotations which follow from $\mathrm{Mr}$. Macleay's paper in the Transactions of the Linnæan Society, and from his "Letter on the Dying Struggle of the Dichotomous System."

But previously to our entering in detail upon this part of the subject, we must, for another purpose, quote and make some remarks upon the remainder of this page of Mr. Rennie's book; it is as follows :"Again, speaking of his discovery of what he calls the nature of the difference between affinity and analogy, Mr. Macleay says, "It is quite inconceivable, that the utmost human ingenuity could make these two kinds of relation tally with each other, had they not been so designed at the Creation.' * In another place he talks of portions of his system being 'almost mathematically proved to be natural $\uparrow$. "' The italics are all Mr. Rennie's. We have in the extract now before us, the first example of a numerous class of misinterpretations of the plainest figures and forms of speech in the English language, which distinguish the present production of this champion, before whose mighty prowess all the discoveries of modern zoology are to be dispelled, like the illusions of fancy before the blaze of truth; a class of errors, which must either have resulted from wilful determination not to understand the representations of the New School of Zoology, as they are used by their authors and designed to be understood by them, or else the most deplorable and unpardonable ignorance of his own language, and of the figures common to all language, which a claimant for literary or scientific honours ever yet displayed. As we shall show in the sequel, the entire drift of this page, is to support the assertion that Mr. Macleay's system and "the natural system" are regarded to be identical. To contribute towards the accomplishment of this purpose, Mr. Rennie puts the word nature above, in italics, prefaced by a "what he calls," meaning to insinuate thereby that in the phrase " nature of the difference between affinity and analogy" is contained an implication that that difference, is, ipso facto, a part of " the natural system," of the system actually existing in nature. Whether this proceeds from effrontery or ignorance, it is equally astonishing; had such a line of argument been related to us of any writer, we should have denounced it as incredible, but here it is before our eyes, and we can but wonder. In order that no ambiguity or pretext for evasion may exist, we shall cite the passage of the "Dying Struggle" in which the word is used by Mr. Macleay. We shall, like Mr. Rennie, distinguish it by the italic character. M. Virey and Dr. Fleming having both endea-

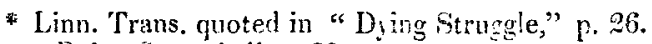

+ "Dying Strugsle," p. 28.

N.S. Vol. 10. No. 59. No\%. 1831.

a $\mathrm{C}$

voured 
voured to fix upon Mr. Macleay the charge of plagiarism, with respecs. to the distinction of relations of affinity from those of anulogy, he observes, "I have however" repeatedly stated that Linnæus, Pallas, and Desfontaines, and even Arristotle himself, have all mentioned certain analogies in nature, as distinct from affinities, before I was born. They have mentioned the existence of this distinction in rarticular cases ; but I first pointed out its nature and its general application, and called the attention of naturalists to the subject." Dying. Struggle, p. 25. Every reader whose progress in literature has advanced one step beyond "The London Primer," and more especially those who have ascended in to the mysteries of that profound storehouse of philology and rhetoric, "Mavor's Spelling Book," will immediately perceive what Mr. Macleay means by the word nature, where he uses it the second time, which is that alluded to by his erudite antagonist. Far be it from us to estimate the extent of Mr. Rennie's attainments as a min of letters; but as we are so unfortunate as to differ essentially from him in opinion in our construction of this word, we must, in our own vindication, explain our views on the point. When, therefore, Mr. Macleay employs the term "nature" of "the distinction of relations of affinity from those of analogy," we humbly conceive that he does not intend to imply that the distinction between those relations is "nature," or the universe, as $\mathrm{Mr}$. Rennie seems to think; any more than we intend, by saying that the nature of Mr. R's attack on the new views in Zoology is at once frivolous and unpriucipled, to imply the existence of nature, or anything like rature, in any of his productions. Mr. Macleay means, that he first pointed out the Natura (to employ the original Latin word, in the sense in which it is used by Cicero and others) of the distinction between those two species of relation, that is, its intimate quality and peculiar characters.

This subject, as it appears to us, illustrates another on which $\mathrm{Mr}$. Rennie enlarges in a previous page: "On my plan [of the study of Natural History,] any person," he observes, "may become a tolerably good naturalist, the first walk be takes in the fields, without much knowledge of books :" in illustration of this plan of study, this mode of making "tolerably good" naturalists with the rapidity of steampower, this new royal road to the knowledge of nature, or Professor Rennie's short cut to scientific fame, we are favoured in page $\mathrm{x}$, by a learned dissertation on the nest of a Dabchick, given as the great type of the proper mode of conducting ornithological investigations. But the author has unconsciously favoured us, in his construction of the word "nature," as above, with a memorable refutation of his own principles of study : to us this is peculiarly consolatory; for we, obtuse wights as we are, were obliged, alas, to take a great many "walks in the fields," and to pore over a great many books too, before we thought ourselves "tolerably good naturalists." But in Mr. R's mode of construing the word "nature" we now have an example before us of the discovery of a phænomenon in nidification far exceeding, in its wonderful character, what the Dabchick's nest would be, even were all the contradictory stories of it true; $\mathrm{Mr}$. Rennie, without even a single "walk in the fields," has discovered 
by the mere study of books, that celebrated and interesting production of nature, often discovered before, it is true, but always of equal interest when rediscovered,-a Mare's Nest.-We are not fond of pleasantry in the discussions of science, but really this blunder is worthy only of ridicule.

To return however to our examination of page xxxii. In the first quotation from the Dying Struggle, Mr. Macleay certainly does strongly affirm his opinion, that the two relations of affinity and analogy co-exist in rature, (to which subject we shall by and by advert in detail,) and were designed so to co-exist, at the Creation. But all he asserts of himself, is, that he, by induction, discovered the nature of the distinction between them, and also the nature of their co-existence; and as truly might the Chemist who has observed that bydrogen, oxygen, and sulphur, enter into combination with each other or with other bodies invariably in proportions represented by the numbers 1,8 , and 16 , or their multiples by a whole number, say, "It is quite inconceivable, that the utmost human ingenuity could make" the proportions in which these bodies combine "tally with each other, had they not been so designed at the Creation." He would describe in these terms, relations which the Creator has been pleased to confer on certain forms of matter; Mr. Macleay does the same, but he does no more; neither does more or less, by using this language, than describe an ascertained phæromenon. Similar is the case with Mr. Macleay's saying that the great groups into which he has discovered the animal kingdom to be distributed, on its first ramification, " are almost mathematically proved to be natural." 'This is just the expression which the chemist again might use, in the actual condition of his science, respecting Dr. Prout's doctrine that all the numbers representing the proportional combining weights of the chemical elements are simple even multiples of the least of them; a doctrine which " is almost mathematically proved to be natural."

We quit the subjects of this introductory page, with the observation that the quotations in it have been made and arranged, either disingenuously or ignorantly, to prove that Mr. Macleay's system claims to be ipso facto the system of nature: if such be not their design, they can have been intended for no purpose whatever, nor do they serve any other.

Sept. $29,1831$.

[To be continued.]

The Life of Sir Humpury $\mathrm{D}_{\mathrm{Avy}}$, Bart. LL.D. late President of the Royal Society, Foreign Associate of the Royal Institute of France, \&c. \&c. By John Ayrton Paris, M.D. Cantab. F.R.S. \&. . Fellow of the Royal College of Physicians.

\section{[Continued from page 923.]}

In the chapter which contains the account of the decomposition of the fixed alkalies, notice is also taken of some of Davy's experiments and discoveries, which though of minor are still of great importance; to these, however, we shall but briefly allude. Among them are an investigation of the nature of Antwerp blue, which proved to be a mixture of Prussian blue and alumina; the production of the vegetation of the carbon of the wict of a candle, $3 \mathrm{C} 2$ 